\title{
A DECOMPOSIÇÃO DOS VIVIDOS (ERLEBNIS) E OS PRESSUPOSTOS DAS APARIÇÕES
}

\author{
THE DECOMIPOSITION OF THE EXPERIENCE \\ (ERLEBNIS) AND THE PRESUPPOSES OF \\ APPARITIONS
}

\author{
Rudinei Cogo Moor \\ Doutorando-UFSM \\ rudimoor@yahoo.com.br
}

\begin{abstract}
RESUMO: O método fenomenológico torna possível a decomposição dos vividos e mostra o que é mais próprio de suas aparições: o sentido que todas carregam, entrelaçadas por momentos intencionais e pressupostos não-intencionais, referidas ao sujeito transcendental. Para Husserl, todo esforço em descrever esses pressupostos não-intencionais das aparições requer uma explicitação da consciência, como ponto de referência de toda objetividade e aparecimento. O presente artigo procura apontar para a relevância dos pressupostos hiléticos e da passividade na elucidação da vida consciente. Na obra Ideias I, Husserl deixa as discussões sobre a hylé em aberto, para direcionar-se às funcionalidades das noeses, consideradas como investigações mais ricas no campo das atividades constitutivas da consciência. Por outro lado, destaca que o sujeito só tem esta autêntica liberdade de tomada de posição ativa, porque possui uma base passiva de receptividade e afetividade pela qual as experiências da vida se constituem, preenchendo-se "das coisas" que se doam a ele. A passividade fornece a matéria para as atividades, desenvolvendo-se por meio de associações enraizadas na vida da consciência, tanto subjetiva quanto intersubjetiva.
\end{abstract}

PALAVRAS-CHAVE: Intencionalidade. Vivido. Noese. Hylé. Passividade. Atividade.

ABSTRACT: The phenomenological method makes possible the decomposition of experiences and shows what is most characteristic of their appearances: the meaning they all bear, intertwined by intentional moments and unintentional presuppositions, referred to the transcendental subject. For Husserl, every effort to describe these unintended presuppositions of the appearances requires an explicitness of the consciousness as a reference point for all objectivity and appearance. This present paper seeks to point to the relevance of hyletic presuppositions and passivity in elucidating conscious life. In Ideias I, Husserl leaves the discussions about the hyle open, in order to address the functionalities of the noeses, considered as the richest investigations in the field of the constitutive activities of consciousness. On the other hand, he emphasizes that the subject only has this authentic freedom to take an active position, because he has a passive basis of receptivity and affectivity by which the experiences of life are constituted, filling in "the things" that are given to it. Passivity provides the material for activities, developing through associations rooted in the life of consciousness, both subjective and intersubjective.

KEYWORDS: Intentionality. Experience. Noese. Hyle. Passivity. Activity.

\section{CONSIDERAÇÕES INICIAIS}

O que significa viver? O início da pergunta "o que" já pressupõe que seria possível objetivar "o que” está sendo pedido para a significação. Para Husserl, somente faz sentido falar desse "viver" se estiver acompanhado de "alguma coisa". Partindo da vivência de algo é possível, em vista de sua aparição, decompô-la (pelo método da redução) e descrevê-la com todo o rigor fenomenológico. "Viver" pressupõe que uma vida já esteja em andamento, e que nela alguma atividade esteja direcionada para algo 
além de si mesma, podendo experimentar-se e constituir-se como vivência e aparecimento. O que aparece, sempre se mostra para um sujeito transcendental, que recebe o dado (Gegebenheit) vivido e o constitui como unidade de sentido. O sujeito não é o causador dessas vivências, mas o polo que as visa e unifica.

Na decomposição dos vividos, Husserl descreve a parte que é própria do sujeito transcendental - suas atividades intencionais de doação de sentido. Por outro lado, o sujeito só tem esse poder de doação, porque possui uma base passiva de receptividade pela qual as experiências da vida se constituem, preenchendo-se "das coisas" que são dadas e que o afetam. Em Husserl, o ponto de partida de todas as descrições da consciência se dá a partir dos vividos. Nesse ponto, há pressupostos que são o fundamento para que o próprio viver se desenvolva, bem como, a essência que constitui o sujeito em sua própria individualidade. Tomando dos vividos tudo aquilo que aparece, Husserl aponta para os pressupostos deste viver que, sem os quais, não haveria vividos.

O artigo segue o seguinte trajeto: a primeira seção visa trabalhar com o conceito de vivido (Erlebnis), destacando o ponto de origem da fenomenologia transcendental de Husserl. Em seguida, a discussão gira em torno do conceito de hylé e noese, remetendo inicialmente à leitura do $\$ 85$ de Ideias $I$, contextualizando e compreendendo os usos relativos do termo hylé com o $\$ 58$ da VI Investigação Lógica, bem como, explicando o motivo de Husserl subordinar a hilética pura à fenomenologia da consciência transcendental. E, uma vez que Husserl se volta aos problemas da constituição, analisarse-á, por último, os componentes de atividade e passividade, destacando a gênese passiva como um pressuposto fundamental tanto para a vida da consciência subjetiva como intersubjetiva, sublinhando o seu desenvolvimento por meio das associações.

\section{A PRIORI QUE É A POSTERIORI: HUSSERL E O FLUXO DOS VIVIDOS}

A consciência se manifesta como um fluxo temporal no qual, as coisas e suas aparições $^{68}$, tornam-se possíveis para um eu em algum momento desse fluxo. Essas aparições são vividas por um sujeito, segundo alguns modos de se relacionar intencionalmente com elas, vivendo-as de acordo com o mundo circundante (Umwelt) no qual elas despontam. A vida do sujeito escorre passivamente no fluxo temporal da

\footnotetext{
${ }^{68}$ No apêndice da sexta investigação lógica, §5 - Os equívocos do termo aparição (Cf. 1975, pp. 180-3) -, Husserl esclarece o termo aparição (Erscheinung) e as confusões que aparecem ligadas a ele, principalmente atravessadas pelo termo de percepção (Wahrnehmung). Para ele, o conceito originário de aparição - e que se seguirá no presente artigo - é o que aparece, do que pode aparecer, do intuitivo enquanto tal, o objeto intuído.
} 
consciência, que não é criado por ele e nem um efeito de suas ações, mas todas as suas atividades se colocam ou aparecem nesse fluxo em que tudo flui passivamente. Husserl compara a consciência como um "fluxo heracliteano" dos vividos (Cf. HUSSERL, 2001, p. 67) em que se encontram os fenômenos da consciência em sua própria imanência, e a subjetividade transcendental como um polo que emerge deste fluxo contínuo, como possibilidade de dar sentido (Sinngebung) e unificá-lo sinteticamente.

"Sem dúvida, a vida da consciência encontra-se em fluxo, e todo cogito se insere numa corrente, sem elementos últimos e relações últimas fixáveis" (HUSSERL, 1992, p. 29). Não é possível dizer algo desse fluxo em si mesmo ${ }^{69}$, mas somente no momento em que se vivencia (presentifica), a partir dos atos que se pode realizar no mundo com os outros sujeitos. A partir daí, as experiências começam aparecer numa unidade desse fluxo. O sujeito está imerso em seu fluxo de vividos de consciência e conforme esse fluxo escoa, sua vida vai se constituindo; coisas novas acabam "aparecendo" nessa vida, sem que ele estivesse consciente disso anteriormente, afetando sua atenção e "exigindo uma resposta" nas situações vividas. A constituição é um tipo de resposta a tudo isso (Cf. GOOSKENS, 2011, p. 183) ${ }^{70}$. Dessa forma, ele pode retomar sua vida que se constitui e orientar uma modificação transcendental, enquanto reflete seus vividos e encontra neles o suporte para uma vida teórica e filosófica.

É válido dizer que vivido (Erlebnis) não significa que o ego está ligado apenas ao seu passado, ignorando o que se passa a ele no presente ou no futuro. Como os vividos estão num fluxo contínuo, o sujeito se encontra direcionado ao que se dá a ele, e isso significa que está "vivendo alguma coisa". Ele pode estar direcionado a uma recordação de algum "evento do passado"; imaginando "Cronos devorando seus filhos"; percebendo um "livro de filosofia"; dividindo uma "fração comum $\frac{\pi}{2}$,; enfim, tudo o que é vivido e operado no momento.

O vivido, Erlebnis em alemão, é aquilo de que se tece nossa consciência enquanto nela escoa uma vida. O que Husserl evoca falando de vividos e

\footnotetext{
${ }^{69}$ Mas não dá para afirmar que o fluxo em si mesmo seja um "nada" ou "vazio", uma vez que já está pressuposta uma corrente imanente do tempo, que se descobre (ou desvela) na medida em que os vividos se desenvolvem nele e por meio dele.

${ }^{70}$ No interessante artigo de Geert Gooskens - Towards a responsive subject: Husserl on affection - o autor apresenta o argumento de que a subjetividade transcendental - entendida e criticada por muitos autores (entre eles Heidegger e Lévinas) de ser um conceito violento, antropocêntrico e de submeter a si mesma todo ser - é, na verdade, um polo responsivo antes mesmo de ser autônomo. Isso se deve a questões de afecção e estímulo que excedem os poderes do ego. Esse ser afetado precede todo ato de consciência, mas quando a esfera subjetiva é afetada num presente, a atividade é uma resposta. A constituição nesse caso, como "produção" das atividades intencionais do eu nada mais é que um tipo de resposta.
} 
de fluxo de vividos não é simplesmente o fato de que temos um teatro íntimo, representações, pensamentos; o fato de que uma vida primordial da consciência não cessa de se manifestar por vividos atados uns aos outros em um fluxo (SALANSKIS, 2006, p. 21, grifos do autor).

No momento que se está direcionado reflexivamente para as vivências, o ego transcendental doa sentido aos vividos que aparecem na correnteza da consciência à qual pertence. Husserl descreve a subjetividade transcendental, afirmando que é um "polo", "doadora de sentido", "eu puro", estrutura universal da consciência, resíduo de uma redução etc. No entanto, ela é o que é em relação aos seus vividos ${ }^{71}$. Como polo de sentido objetivo, todos os vividos que passam pelo fluxo da consciência têm a possibilidade de serem constituídos por ela. Mas, e os vividos que escorrem pelo fluxo e não são tematizados pelo ego puro, que passam e se esvaem? E o que antecede a consciência, o pré-dado, que ganha sentido de dado, na medida que vai fluindo, passando a se dar como objetivo? O que ocorre com o pré-dado? O que ele é antes de ser visado? Como fazer com que aquilo que é pré-dado possa se mostrar por si mesmo? O que se pode saber sobre esta "objetividade originária” (Urgegenständlichkeit) senão o que aparece ${ }^{72}$

Para Salanskis, Husserl distingue dois tipos de vividos:

a) Vividos hiléticos: é difícil dizer com precisão como se dão os objetos dos vividos hiléticos, uma vez que, para Husserl, ainda não são "objetivos", mas simples materiais para a vida da consciência. Eles são a base pela qual a consciência pode exercitar suas atividades anímicas. A consciência pressupõe essa base concreta da vida para constituir seus noematas. Assim, “esses vividos são uma espécie de dado que a imanência encontra em si mesma após a redução, eles são o elementar da sensação e do sentimento" (SALANSKIS, 2006, p. 60, grifos do autor). Sobre isso se explorará na próxima seção deste artigo.

b) Vividos que participam da intencionalidade: a intencionalidade não tem a capacidade de criar por si mesma o fluxo de vividos, pois é dependente desta base dos vividos hiléticos, e ela se edifica "graças à colaboração destes” (SALANSKIS, 2006, p.

\footnotetext{
71 “O ego transcendental (...) é aquilo que ele é unicamente em relação aos objetos intencionais" (HUSSERL, 2001, p. 81).

${ }^{72}$ Parece que Husserl não responde algumas dessas questões e parte sempre do que é dado na correlação da consciência. No entanto, não deixa de destacar que o campo intencional se constitui por elementos que são não intencionais. É relevante sublinhar alguns autores, entre eles Marion, Michel Henry, Bernhard Waldenfels, entre outros, que questionam essa objetificação da manifestação. Husserl parte do dado, mas isso não significa que todo dado é objetivo, como, por exemplo, a experiência do outro é dada, mas o outro não é objeto.
} 
60), que remetem a consciência para fora de si mesma na medida em que afetam o sujeito. Os vividos hiléticos participam de um momento na constituição dos noemas, que são as unidades de sentido dos conteúdos das múltiplas noeses que animam a hylé. Os vividos têm seus momentos e componentes que se constituem enquanto tais. $\mathrm{Na}$ decomposição dos vividos, além dos momentos intencionais (noéticos e noemáticos), em sua constituição, encontra-se a temporalidade, a matéria (hylé), o mundo, os sujeitos psicofísicos e suas relações de sentido com tudo aquilo que está pressuposto, bem como, a cultura, história, as ciências etc. Husserl não se propõe a dar uma descrição progressiva, na qual cada elemento constituinte vai evoluindo e se encaixando a partir de um começo ${ }^{73}$. Para Husserl, o relevante é "voltar às coisas mesmas", partir da origem em que tudo se manifesta, que são as doações das vivências. O trabalho do fenomenólogo é a descrição e análise intencional do modo como essas vivências se doam. Os elementos que dão suporte aos vividos são pressupostos por Husserl ${ }^{74}$, pois, do mesmo modo que para ter acesso ao passado ou futuro o ponto de referência é sempre o presente, assim também o é para o que antecede a consciência. Por isso, o que seria a posteriori, Husserl toma como a priori, ou seja, é preciso partir do que é dado intuitivamente para a consciência, pois somente através dela é que se pode saber algo do que antecede e aponta para a própria manifestação que torna possível estas "coisas mesmas".

\section{HYLÉ E NOESE}

No $§ 85$ das Ideias I Husserl se propõe fazer uma distinção entre $Y \lambda \eta$ sensual (hylé) e $\mu о \rho \varphi \eta$ intencional (morphé), tomando os vividos tais como se mostram na reflexão imanente. A característica do fluxo de vividos, como uma unidade da consciência, é a intencionalidade, e isso vale também para aqueles vividos que se caracterizam como não-intencionais ${ }^{75}$, mas que dependem da intencionalidade para poderem "vir à luz" como objetividades, indicarem sua anterioridade ao tornarem-se consciência de algo. Aqui, neste parágrafo, o filósofo se abstém "de descer às escuras

\footnotetext{
73 "Para a fenomenologia genética, a origem, Ursprung, não é um começo, Anfang" (ALVES, 2019, p. 23).

${ }^{74}$ É valido lembrar que a fenomenologia de Husserl se caracteriza por realizar uma descrição livre de pressupostos, mas isso não significa que tais pressupostos são negados, apenas suspensos pelo método fenomenológico.

${ }^{75}$ No §10 da V Investigação Lógica Husserl aponta para as sensações como vivências não-intencionais: "Que nem todas as vivências sejam [intencionais], mostram-no as sensações e complexos de sensações" (2015, p. 317).
} 
profundezas da consciência última, constitutiva de toda a temporalidade dos vividos" (2006, p. 193) para se ocupar dos vividos como unidades de eventos temporais mostrados na reflexão. Assim, “em todo domínio fenomenológico (...) um papel dominante é desempenhado pela notável duplicidade e unidade da $Y \lambda \eta$ sensual e da $\mu о \rho \varphi \eta$ intencional"' (HUSSERL, 2006, 194, grifos do autor).

Para contextualizar o termo que chamará de hyle ${ }^{76}$, em nota de rodapé das Ideias I, Husserl aponta para sua obra Investigações Lógicas, na qual trabalhava com os vividos a partir do conceito de "conteúdo primário", para designar os conteúdos sensíveis e "externos", que posteriormente na obra Ideais I o abandona por julgar impreciso. A título de menção, no $§ 58$ da Sexta Investigação Lógica, há uma diferença fenomenológica essencial, referidos ao domínio da sensibilidade, entre conteúdos primários $(\mathrm{CP})$ e os conteúdos da reflexão $(\mathrm{CR})$. Os $\mathrm{CR}$ "são caracteres de atos ou fundados em caracteres de atos" (HUSSERL, 1975, p.140), pois, em certa instância, todos os caracteres de atos são fundados em conteúdos sensíveis (que são fundantes). Por isso, os CP, sendo referentes aos conteúdos vividos da sensibilidade "externa", "são aqueles conteúdos nos quais todos os conteúdos da reflexão são fundados mediata ou imediatamente" (HUSSERL, 1975, p.140).

Por mais que a reflexão tenha seus próprios conteúdos intencionais (ou CR), ela é fundamentada por meio dos $\mathrm{CP}$, ainda que do modo mais livre possível, não se estreitando puramente a eles. Há certa anterioridade dos CP assim como os vividos irrefletidos, mas só é possível saber disso através da reflexão ${ }^{77}$ (Cf. HUSSERL, 2006, p. 178).

Na obra Ideias I (§85), fazem parte dos CP certos vividos "sensuais" que se unificam como generalidade de "conteúdos de sensação" e se diferem do "momento noético da sua aparição" das coisas sensíveis, que se estende também às sensações de prazer ou sofrimento e seus momentos sensuais. Enquanto os "conteúdos de sensação"

\footnotetext{
76 “Termo grego que significa 'matéria' (lenho em Aristóteles) e que, em Husserl, assume o sentido de vivência sensível, afetiva e imanente, habitando passivamente minha consciência de sujeito" (Depraz, 2007, p. 118). Segundo Salanskis, "matéria e forma (morphé) classicamente se opõem em filosofia, pelo menos desde Aristóteles, que deu uma grande importância a este par de termos, particularmente para caracterizar o objeto daquilo que ele chama física" (2006, p. 60).

${ }^{77}$ Husserl, no $\$ 58$ das Ideias II, pergunta se o eu pessoal se constitui sob a base das reflexões do eu - se é preciso recorrer à experiência reflexiva para que a unidade de eu pessoal possa chegar a ser consciente, ou se já está consciente na predação, "antes de que haja sido originalmente dado mediante tais séries de experiências identificadoras e realizadoras que, enquanto reflexões sobre as cogitações, põe a vista no comportamento em referência às circunstancias? Mas o que se organiza então nas esfera pré-reflexiva? Seguramente se formam 'associações', se desenvolvem indicações prospectivas e retrospectivas como no caso dos 'fundos' sensíveis e coisificadas desatendidas” (HUSSERL, 2005, p. 299, grifos do autor).
} 
são aquilo que se pode constatar nas coisas como dados de cor, de tato, de sabor, de som etc., os "momentos de aparição" são os vividos intencionais por meio desses dados, isto é, se exibem por meio dos conteúdos de sensação, tais como coloração, dureza, doçura, agudeza etc. Num exemplo: há uma diferença entre "a cor branca da folha de papel A4" que é sensual (dados de cor sensível) e "externa"; outra é o momento em que se experimenta, se vivencia e se constata sua coloração branca intencionalmente. Portanto, "a partir do sensual, que nada tem de intencionalidade em si" (2006, p. 194) há uma camada que dá sentido, isto é, os atos subjetivos intencionais animam $^{78}$ estes componentes sensuais, conferindo-lhes uma direcionalidade intencional específica, tornando-os conteúdos de alguma coisa ${ }^{79}$.

É digno de nota afirmar que na leitura deste $\S 85$, Michel Henry comenta que "a essência da hylé é determinada desta maneira: positivamente, por pertencer à realidade da subjetividade absoluta, como constitutiva de seu tecido, de seu próprio ser; negativamente, pela exclusão fora de toda intencionalidade" $\left(2009\right.$, p. 42-43) ${ }^{80}$. Em outro escrito, Henry confirma o apontamento que o artigo se propõe, de que Husserl não ignorou o não-intencional, designando-o como hylé. Segundo o autor, hylé não é um simples componente da consciência, mas o que permite à consciência ser consciência, dando-se a si mesma antes de qualquer coisa (Cf. 2006, p. 13-14). A crítica de Henry, em parte nesse texto, mas no geral da sua fenomenologia material, é que a fenomenologia intencional acabou reduzindo a fenomenalidade, deixando escapar os modos originais e fundamentais do aparecer como a fenomenalidade se fenomenaliza.

\footnotetext{
78 "Podemos distinguir na consciência um ato animador que confere aos fenômenos hiléticos um sentido transcendente: esses fenômenos significam algo do mundo exterior, eles o representam, o querem, o amam, etc. Este ato é um elemento que, por um lado, tem um modo de existir idêntico ao dos dados hiléticos, isto é, é consciente e se constitui no tempo imanente. Ele conhece a si mesmo dessa maneira implícita que caracteriza as vivências ou estados de consciência. No entanto, dá sentido ao fluxo da consciência. "Intenciona" algo que não é ele, se transcende a si mesmo" (LÉVINAS, 2004, p. 67-68).

${ }^{79}$ Husserl deixa algumas questões em aberto neste $\$ 85$ e diz não ser ai o lugar para decidir "se, no seu fluxo, tais vividos intencionais comportam em toda parte e necessariamente alguma 'apreensão vivificante' (com todos aqueles caracteres que esta por sua vez implica e possibilita) ou, (...) se elas sempre se encontram em funções intencionais. Por outro lado, também podemos deixar ainda em aberto se os caracteres que produzem essencialmente a intencionalidade podem ter concreção sem base sensual" (2006, p. 194).

${ }^{80}$ Para Michel Henry essa definição positiva e negativa coloca frente a frente duas questões abissais: a) "Como pode a essência da $v ́ \lambda \eta$, excluir de si mesma a intencionalidade, e ainda ser capaz de se unir a ela no seio da subjetividade absoluta?" (HENRY, 2009, p. 43) e b) "Como pode definir o momento real dessa subjetividade, intervir nela a título de constituinte real, se a morphé intencional é investida com o mesmo poder e o mesmo status?" (HENRY, 2009, p. 43). Essas perguntas são relevantes para saber, no final das contas, qual das duas (a hylé não intencional ou a morphé intencional) constitui em último lugar a subjetividade. Para Henry, Husserl deixou sem solução o problema fundamental da unidade ad intra da consciência, do entrelaçamento entre componentes hiléticos e intencionais da experiência e como isso reside na própria subjetividade absoluta. Na interpretação husserliana esses componentes se relacionam um ao outro para formar assim os fenômenos (Cf. HENRY, 2009, p. 47).
} 
O sentido é de outra ordem do sensual, não faz com ele uma relação de causa e efeito. No entanto, o sensual é a base indispensável para a realização do sentido. Em outras palavras, sem material (hylé) não há possibilidade alguma de sentido. Retornando ao exemplo, na percepção, quando a folha A4 estiver dada para um sujeito que a visa, ela passa a ser experimentada enquanto tal (como dado de cor branca, ou algo que pode ser utilizado como possibilidade de um escrito, um esquema filosófico, um desenho...), torna-se objeto intencional para um sujeito, que esquematiza e imprime seus conceitos ou uso próprio, podendo ser verificados na própria folha. A folha, por si só, não tem nada de intencional, a não ser se estiver dada para alguém que a vivencia no momento, por meio de seus atos noéticos intencionais que lhe conferem sentido. Mas, antes de haver esse direcionamento para a folha de papel e perceber sua brancura, ela estava ali, precedente ao ser notada intencionalmente, pois passivamente já se encontrava como parte fundamental e possível do fenômeno constitutivo. Portanto, não se trata de duas coisas diferentes, pois em todos os casos é a folha de papel branca A4. A diferença se deve ao "momento" em que ela entra no fluxo dos vividos, em que é percebida, e o momento em que ela estava fora do campo da percepção.

A análise fenomenológica parte do vivido que é unificado pela subjetividade transcendental, o que significa partir não do ego ou do objeto, mas do que se vive no ato intencional. Husserl esclarece melhor no $\$ 36$, quando fala do vivido intencional, no contexto da intuição perceptiva do papel branco:

\begin{abstract}
No vivido de percepção desse papel branco, mais precisamente, nos seus componentes referidos à qualidade "branco" do papel, encontramos, por direcionamento adequado do olhar, o dado de sensação "branco". Esse branco é algo que pertence inseparavelmente à essência da percepção concreta, enquanto seu componente concreto real. Como conteúdo exibidor do papel que aparece, ele é suporte de uma intencionalidade, mas não ele mesmo uma consciência de algo. O mesmo vale para outros dados de vivido, por exemplo, os chamados sentimentos sensíveis (2006, p. 90, grifos do autor).
\end{abstract}

Para adequar uma terminologia mais adequada acerca das "camadas sensíveis" e intencionais, Husserl evita o conceito "conteúdo primário" (CP) das Investigações Lógicas, bem como, toma certo cuidado com "vivido sensível" (VS) e "sensibilidade" (S). O termo usado, portanto, será o de "dados hiléticos" ou "materiais" para falar das "camadas sensíveis". CP não "parece suficiente como designação" (HUSSERL, 2006, p. 194), assim como VS indica um distintivo "sensível” à percepção, intuição... caracterizando-os como vividos intencionais e não vividos hiléticos. A palavra sensível é mantida, em certo sentido, após a redução, como sensibilidade, abarcando os 
sentimentos e impulsos sensíveis (prazer ou dor, alegria ou tristeza, satisfação ou decepção etc.), bem como, sensibilidades mais estritas, como conteúdos sensíveis (como $\mathrm{CP})$. A hylé expressa a unidade de função dos caracteres formantes, onde os aspectos que são abarcados pelo termo sensibilidade levaram a mudança para os campos da afetividade e da vontade, nos quais esses aspectos são tomados como "materiais funcionais", pois são os substratos que, sem os quais, não haveria possibilidade de função noética nenhuma.

É preciso atentar para o seguinte: a matéria (hylé) que serve de suporte, não pode ser confundida com o objeto intencional propriamente dito (noema) ${ }^{81}$, por mais que ela, em algum momento, tenha a possibilidade de "vir-a-ser" visada intencionalmente ${ }^{82}$. O alinhamento entre hylé e o que a anima, a noese, é o "vivido" enquanto tal, e é o vivido “o" a priori das investigações de Husserl nas Ideia I. Da mesma forma, por mais que o nome matéria possa indicar coisas materiais exteriores, isso não significa que hylé seja reduzida a isso, uma vez que há uma hylé necessária para a constituição da imaginação, dos afetos, dos sentimentos e assim por diante. Comentando este $\$ 85$ das Ideias I de Husserl, Lévinas chama a atenção que os dados hiléticos não podem ser igualados ao conceito de sensação dos sensualistas ${ }^{83}$, pois os mesmos denominavam sensações com o que os sentidos podem captar da exterioridade. Para a fenomenologia, hylé aponta para além da exterioridade, entrelaçando a esfera da afetividade e da vontade.

Para opor os dados hiléticos às sensações dos sensualistas, ainda é necessário salientar que o princípio da unidade própria dos conteúdos reunidos sob o conceito de hylé não é sua mera exterioridade, pelo fato de que provém de nossos sentidos - com o qual o empirismo estava satisfeito - senão seu caráter interno, que nos permite entender a noção de hylé além do que é dado pelos sentidos, para levá-lo à esfera da afetividade e da vontade. No entanto, o fluxo

\footnotetext{
81 “O noemático é o campo das unidades, o noético, o campo das multiplicidades 'constituintes' (HUSSERL, 2006, p. 228).

${ }^{82}$ Com relação da diferença dos componentes hiléticos e noéticos dos componentes do noema, Husserl diz no §97: “(...) a unidade real de vivido dos componentes hiléticos e noéticos é totalmente diferente da unidade das partes componentes do noema, "trazida à consciência naquela primeira"; e diferente, mais uma vez, da unidade que unifica todos os componentes reais do vivido com aquilo que, neles e por meio deles, vem à consciência como noema. Sem dúvida, o 'transcendentalmente constituído' 'com base' nos vividos materiais 'mediante' as funções noéticas é um 'dado', e um dado evidente, se em intuição pura descrevemos fielmente o vivido e aquilo de que nele se é noematicamente consciente; mas ele faz parte do vivido num sentido totalmente diferente dos constituintes reais e, portanto, próprio dos vividos" (2006, p. 225, grifos do autor).

${ }^{83} \mathrm{Na}$ obra "Conferências em Paris" Husserl aponta que, se a análise fenomenológica sobre dados sensoriais tem de mostrar alguma coisa, então não deve ser algo primário das "percepções externas”, mas o que é dado na intuição, segundo seu sentido como objeto e nos modos de sua manifestação. Isso faria evitar interpretar a consciência de acordo com o sensualismo. Para Husserl, "é uma invenção construtivista do sensualismo interpretar a consciência como complexo de dados sensíveis, eventualmente acrescentar-lhe depois qualidades morfológicas e deixar ao cuidado destas a totalidade" (1992, p. 21).
} 
da consciência não é apenas composto da camada hilética (LÉVINAS, 2004, p. 67).

Enquanto a hylé é uma camada não-intencional do fluxo da consciência, o momento noético ou nous $^{84}$ - forma (morphé) - é a camada intencional, que anima e doa sentido, formando "as matérias para os vividos intencionais" (HUSSERL, 2006, p. 195) e especificando que tipo de intencionalidade se encontra em todos os vividos da consciência. Para Husserl, "o fluxo do ser fenomenológico tem uma camada material e uma camada noética" (2006, p. 197, grifos do autor), e as considerações e análises fenomenológicas podem ser divididas a partir destas duas camadas, quando se referem ao material - hiléticos-fenomenológicas; quando aos momentos noéticos - noéticofenomenológicos. Para o filósofo, "as análises incomparavelmente mais importantes e ricas se encontram do lado noético" (HUSSERL, 2006, p. 197), pois em parte, os momentos noéticos podem realizar atividades mais plenas de sentido com o que é dado de sentido. Dessa forma, afirma:

Graças a seus momentos noéticos, todo vivido intencional é justamente vivido noético; é da essência dele guardar em si como um "sentido" e, eventualmente, um sentido múltiplo, é de sua essência efetuar, com base nessas doações de sentido e junto com elas, outras operações que se tornam justamente "plenas de sentido" por intermédio delas. (HUSSERL, 2006, p. 203).

E como fica a questão da hilética para a fenomenologia, uma vez que Husserl privilegia os momentos noéticos como análises mais importantes e ricas? Ali nas Ideias $I$, §86, é dito que um dos grandes problemas das análises e investigações da fenomenologia transcendental são os "problemas funcionais", ou seja, problemas que dizem respeito à “constituição das objetividades na consciência” (2006, p. 197, grifos do autor). Em outras palavras, o problema consiste em saber como ocorre esse entrelaçamento complexo entre consciência e objetividades, ou como os momentos noéticos animam a hylé de modo objetivo, conferindo-lhe sinteticamente uma unidade de sentido a partir dos múltiplos modos de visagem intencional e que podem ser atestados pela própria consciência de si.

Para Husserl, o ponto de vista central da fenomenologia transcendental é o ponto de vista da função, do "modo - como". Todos os "momentos" pertencentes aos vividos

\footnotetext{
84 "Husserl toma o cuidado de relembrar que a palavra noese, escolhida por ele, contém o radical nous, que junto aos gregos designa o espírito no sentido forte da palavra, reenviando à mais alta noção de norma e ao mais espiritual conceito de sentido. A 'doação de sentido' que tem lugar cada vez que a forma se equilibra, valendo interiormente como regra, por um lado é 'advento de sentido'; em linguagem idealista, diríamos que ela é a espiritualidade e a idealidade do sentido afirmando-se ou efetuando-se graças ao fluxo, diretamente pelo fluxo" (SALANSKIS, 2006, p. 64).
} 
da consciência estão de certo modo "a serviço" da constituição transcendental da consciência, inclusive os momentos dos vividos particulares que podem ser vistos sob o ponto de vista teleológico, visando uma unidade sintética, assim como a hylé que proporciona possíveis formações intencionais para os vividos. Por isso, do ponto de vista da análise fenomenológica eidética, mesmo possuindo seu valor em si mesma, "a hilética pura se subordina à fenomenologia da consciência transcendental" (HUSSERL, 2006, p. 199, grifos do autor), pois depende de um ponto de vista funcional para receber significação da parte noética. A partir do momento em que se considera esse ponto de vista funcional da consciência, a investigação direciona-se para o sentido que ela doa para este material, portanto, trabalhando com o seu objeto intencional que é constituído pela consciência.

\section{ATIVIDADE E PASSIVIDADE}

Para Husserl, a subjetividade transcendental é ao mesmo tempo ativa e passiva $^{85}$, em face de si mesma, dos outros e do mundo. Aquilo que é pré-constituído e pré-dado pode ser traduzido para a consciência atual como significações, ou seja, certo tipo de idealidade que se constitui para a consciência transcendental, permitindo acesso aquilo que já se encontra dado aí. Ser e consciência tornam-se um na concreção única da subjetividade transcendental, cuja relação não pode ser reduzida a mera exterioridade, mas na relação que comporta o sentido imanente da constituição. Assim, se a subjetividade transcendental é o universo do sentido possível, então seria um contrassenso falar dela como pura exterioridade, mas o que dá sentido a esse exterior (Cf. 2001, p. 99). Para Husserl:

Não existem primeiro coisas e, em seguida, se insinuam na consciência de modo que o mesmo penetrou aqui e além, mas consciência e consciência, um cogito e outro conectam-se num cogito que ambos une, o qual, como uma consciência nova, é por seu turno consciência de algo e é, sem dúvida, a realização desta consciência sintética de que nela se conhece 'o mesmo', o um como um” (1992, p. 26, grifos do autor).

Por isso, uma decomposição que coloca de um lado as coisas e de outro a consciência é meramente ilustrativa, pois tudo se dá na unidade da correlação intencional. Da mesma forma, o que se dá anterior à consciência é também consciência,

\footnotetext{
${ }^{85}$ Sobre a origem do termo passividade: "a noção de passividade deriva etimologicamente das palavras latinas passio e patior, traduções das palavras Gregas pathos e paskein, respectivamente. No uso ordinário, o verbo grego paskein significava estar em situação ruim ou ser maltratado por alguém”" (BICEAGA, 2010, p. 69). 
pois depende dela para ser explicitada. No entanto, como foi dito, isso não significa que a consciência seja o começo, mas, sim, a origem, isto é, não é ela a causa do início e do fim dos aparecimentos, mas o ponto de partida do qual todo o aparecer se torna possível, ou melhor, o fluxo heracliteano em que o universo dos vividos aparece como real no transcorrer mesmo deste fluxo (nos modos de transcorrer do passado-presente-futuro), encadeados por um sistema constituinte de motivações e em conformidade com as leis da gerais da gênese (Cf. HUSSERL, 2001, p. 91).

Husserl parte dos vividos, que são a origem de toda experiência e consciência possível, evitando o "perigoso" termo causalidade e empregando motivação ${ }^{86}$. Nesse sentido, "na perspectiva husserliana, a motivação é a lei fundamental da vida do espírito e, consequentemente, do mundo e da cultura. Com efeito, a motivação só pode ser compreendida através da relação com a intencionalidade" (FABRI, 2007, p. 135). Ou como Husserl afirma:

O fato de que uma natureza, de que um mundo da cultura e dos homens com suas formas sociais, etc. existam para mim, significa que experiências correspondentes me são possíveis, ou seja, que, independentemente da minha experiência real desses objetos, posso a todo momento realizá-las e desenvolve-las num certo estilo sintético (2001, p. 92, grifos do autor).

$\mathrm{Na}$ corrente do fluxo dos vividos da consciência, a intencionalidade, segundo suas modalidades, vai visando seus objetos de acordo com suas essências e horizontes e, por assim dizer, realizando uma síntese na forma de identificação, que inicialmente transcorre passivamente como consciência contínua do tempo (Cf. HUSSERL, 2001, p. 59). A constituição envolve um processo ativo e passivo da consciência, pois "o fluxo de vivido jamais pode se constituir de puras atualidades" (HUSSERL, 2006, p. 88, grifos do autor), dando-se a partir de seu fluxo temporal que é responsável pela síntese

\footnotetext{
${ }^{86}$ No §56 das Ideias II Husserl explica o porquê da motivação ser distinta da causalidade no sentido das ciências da natureza. Para ele, uma investigação causal, por mais ampla que seja, não pode dar conta das motivações que levaram uma pessoa a ter tal comportamento, pois a causalidade tem como correlato leis da natureza, que podem determinar-se segundo circunstâncias unívocas da própria natureza física. De outro modo, quando se fala de motivação, suas leis são correlatas ao espírito. O comportamento, por mais ligado que está com o corpo psicofísico (processos fisiológicos, sensoriais etc.) não é motivado por essas questões, ou seja, não "lhe" determina espiritualmente. (Cf. 2005, p. 278). A motivação também pode ser entendida como uma unidade, ou seja, “(...) a unidade ininterrupta da corrente da consciência é uma unidade de motivação. Na atitude pessoal isso quer dizer: cada ato no eu é sujeito à constante apreensão pela qual é caracterizado como um ato 'do' eu, como 'minha' experiência." (2005, p. 275).
} 
passiva $^{87}$. A vida transcendental da consciência do ego se desenvolve nessas duas gêneses de atividade e passividade. A primeira se preenche na intencionalidade atual sobre o dado, mas remete sempre à síntese passiva, possibilitando o ego transcendental auto-constituir-se e constituir os objetos num horizonte do mundo e intersubjetivo.

O ego transcendental, como um "eu idêntico" vive, ativa e passivamente, "em todos os estados vividos da consciência e que, por intermédio deles, se liga a todos os polos-objeto" (HUSSERL, 2006, p. 82, grifos do autor). Assim, o eu não é apenas um polo de referência vazio a esses objetos, como se os objetos viessem suprir uma lacuna da consciência, mas o substrato dos "habitus", pois os atos efetuados passam pelo fluxo da corrente da consciência e o eu, que efetua todos esses atos, permanece, como idêntico, formando um habitus, o qual ele pode sempre acessar como pertencente a si. Há sempre a possibilidade de transformação, pois as convicções que formam esse habitus são relativamente permanentes, suas posições ativas modificam-se, mas o eu, no meio dessas modificações mantém um estilo constante, um caráter pessoal (cf. 2001, p. 84).

A atividade do ego, ou seja, sua gênese ativa, é referida, por Husserl, à parte prática da razão, pois "o eu intervém como fator que engendra, cria e constitui com ajuda de atos específicos dele. Todas as funções da razão prática, no sentido amplo da palavra, pertencem a ela" (2001, p. 93, grifos do autor). Os atos do eu se entrelaçam mutuamente com a comunidade sintética unindo-se “em sínteses múltiplas da atividade específica e, com base em objetos já mostrados, constituem de maneira original os objetos novos" (HUSSERL, 2001, p. 93, grifos do autor). "A gênese ativa designa esta manutenção de atos antigos do eu em atos novos; ela se acha nos atos de nível superior, tal como a convicção adquirida, a evidência habitual e de modo geral os habitus" (RICOEUR, 2009, p. 210). No entanto, Husserl lembra no $\$ 54$ das Ideias II que o eu ativo, que toma posição, é apenas um dos lados, pois frente a ele sempre está a passividade no sentido de receptividade e afetividade.

Frente ao ativo está o eu passivo, e o eu é sempre, onde é ativo, ao mesmo tempo passivo, tanto no sentido de afetivo como de receptivo que obviamente não exclui que possa também ser meramente passivo;

\footnotetext{
87 “(...) já nas sínteses passivas de tempo, onde ainda não se pode falar de intenções, como também nas aspirações instintivas e em toda a dimensão afetiva da consciência, no nível em que é afetada pela hyle e que é pressuposto em todas as atividades superiores, Husserl descobre que a vida da consciência é teleológica" (KOLREC, 2013, p. 345).
} 
'receptividade' é, desde já, segundo o sentido, uma expressão que envolve um nível ínfimo de atividade, senão também a autêntica liberdade da tomada de posição ativa. Subjetivo no sentido original também é o eu 'passivo' (em um segundo sentido), na medida em que o eu das 'tendências', que experimenta estímulos das coisas e aparências, é atraído e apenas cede à atração (HUSSERL, 2005, p. 261, grifos do autor).

Nas Meditações Cartesianas a gênese passiva é referida como uma camada inferior, mas sempre necessária, pois se trata da base receptiva da consciência ${ }^{88}$, que recebe o objeto percebido e doa-o para as atividades constitutivas, que encontram esse algo como pressuposto para suas realizações. Para Ricoeur, "pode-se perfeitamente desfazer, a unidade perceptiva da coisa pela 'análise intencional', mas o objeto continua aparecendo como "acabado"” (2009, p. 210, grifos do autor), dado como "pronto" em sua unidade de sentido, identificados pela síntese passiva em um processo contínuo. "Enquanto essas atividades cumprem suas funções sintéticas, a síntese passiva, fornecendo-lhes "a matéria", continua a desenvolver-se" (HUSSERL, 2001, p. 94). Assim,

(...) encontramos as leis essenciais de uma constituição passiva das sínteses sempre novas que, em parte, precedem qualquer atividade e, em parte, a abrangem; encontramos uma gênese passiva das percepções múltiplas como formações persistentes sob a forma de habitus, que aparecem para um eu central como dados previamente formulados e que, tornando-se atuais, afetam o eu e o inclinam à ação. Graças a essa síntese passiva (que engloba dessa forma a obra da síntese ativa), o $\mathrm{eu}$ está sempre rodeado de 'objetos'. O fato de tudo aquilo que afeta o meu eu - o eu do ego 'plenamente desenvolvido' - ser percebido como 'objeto', como substrato dos predicados a serem conhecidos, deve-se já a essa síntese passiva (HUSSERL, 2001, p. 95, grifos do autor).

Como a gênese passiva se desenvolve? Para Husserl, a gênese passiva está sempre produzindo intencionalidades novas, com a mínima participação ativa do eu. Isso significa que ela se desenvolve por meio de $\operatorname{associações~}^{89}$, que são intencionais (Cf.

88 “A receptividade não é mera ordenação de dados caóticos. Em fenomenologia, a sensibilidade já implica um estar aberto a um sentido que não vem de uma escolha voluntária ou de uma livre decisão" (FABRI, 2007, p. 138).

${ }^{89}$ Na obra Conferências em Paris (1992), Husserl afirma em relação a associação como desenvolvimento da gênese passiva: "desponta aqui uma fenomenologia da associação, cujo conceito e origem recebe um rosto essencialmente novo; sobretudo, já mediante o conhecimento, a princípio estranho, de que associação é um título medonho para uma regularidade essencial, um a priori inato, sem o qual o ego é impensável enquanto tal” (HUSSERL, 1992, p. 38). Nas Ideias II, §58, diz também: "temos legalidades, como as encontradas sob o título 'associação', que pertencem ao fluxo de experiências com toda a sua composição, ou seja, tanto às cogitações aqui apresentadas quanto às outras experiências" (HUSSERL, 2005, p. 299). Para Urbano Ferrer y Sérgio Sánchez-Migallón as associações passivas mais importantes são: a) Pré-intencionais: são associações que configuram os conjuntos sensoriais; b) Longitudinalmente intencionais: são as associações das direções da consciência imanente do tempo; e c) Noemáticamente intencionais: são motivações induzidas que antecipam conteúdos com anterioridade aos juízos. Para os 
2001, p. 96). A atividade encontra os objetos dados de antemão, por que há associações que tornam os objetos possíveis através constituição passiva da consciência. Ao falar de associação, Husserl cuida com que esse conceito ganhe uma significação inteiramente nova, distanciando-se do conceito antigo de associação, vindo desde Hume, que é uma deformação naturalista, "segundo o qual os dados 'psíquicos' combinam-se, algo como uma gravitação psíquica" (HUSSERL, 2001, p. 96). Para Husserl, associação não é apenas isso, mas "abrange um conjunto extenso de leis essenciais da intencionalidade que presidem a constituição concreta do ego puro; ela designa uma região de a priori 'inata', sem a qual um ego como tal teria sido impossível”' (HUSSERL, 2001, p. 96, grifos do autor).

Ao mesmo tempo que preside e orienta a constituição concreta do ego puro, a associação está originalmente enraizada na vida da consciência tanto da subjetividade como da intersubjetividade. A subjetividade se vê encarnada, é um corpo. Na percepção do outro, um corpo semelhante se manifesta como um organismo, presente e vivo. Há algo nesses organismos (tanto do eu quanto do outro) que se manifestam originalmente, como uma "“criação primitiva' que conserva seu movimento vivo e ativo" (HUSSERL, 2001, p. 126). Entre o corpo subjetivo e o corpo estranho, Husserl se permite realizar uma analogia, pois nas duas esferas, a essência que se mostra e "orienta" a constituição concreta da vida não se pode ser objetivada, ou melhor, percebida (Cf. HUSSERL, 2001, p. 126). Nesse sentido, quando dois egos se mostram num emparelhamento (Paarung) - que, segundo Husserl, se transforma em grupos, na multiplicidade - há entre eles uma síntese passiva primitiva, que permite que as relações se associem formando um par, ou seja, "os dois sujeitos, assim emparelhados, o são em sua carne, a saber, não somente em seus corpos, mas também em toda a sua vida íntima, psíquica, intelectual e espiritual” (DEPRAZ, 2007, p. 83).

"No caso da associação e da percepção do alter ego pelo ego, (...), o emparelhamento só acontece quando o 'outro' entra no campo de minha percepção" (HUSSERL, 2001, p. 127). Neste emparelhamento há uma constituição passiva entre os dois sujeitos, que reúnem elementos, permitindo que se façam certos tipos de distinções, independentemente se o sujeito se volte ativamente para si mesmo ou não. O "eu" se

autores, com o campo de associações surge um conceito de intencionalidade mais enriquecido e completo, mas ao mesmo tempo se descobre a impossibilidade objetivante que existe nesse fundo de passividade (Cf., 2011, p. 38). 
distingue do outro e se nota como organismo de modo primordial e original através do seu corpo, sendo afetado por ele como um organismo num sentido específico, carnal. Se o outro entra nesta esfera, como um corpo parecido com o do "eu", isso significa que ele também é elevado a significação de organismo, que se manifesta e é afetado por ele, no qual o sujeito já o percebe como um "outro eu", antes mesmo que possa ativamente se dar conta disso.

Para Husserl, a associação é importante para a constituição do fenômeno do outro. Mas esta associação não é imediata, pois parte do corpo e de seu comportamento para evidenciar algo pressuposto que não pertence à constituição subjetiva do eu, mas pertencente ao outro que, todavia, pode ser compreendida pelo eu, tendo a possibilidade de criar associações sempre novas e recíprocas, "posto que toda associação em par é reciproca" (HUSSERL, 2001, p. 134).

\section{CONSIDERAÇõES FINAIS}

Os resultados do trabalho mostram que Husserl não ignorou os pressupostos das aparições. O modo que Husserl explicita a vida da consciência, baseado em seu método de redução, faz parecer que o fenomenólogo não viu questões que eram centrais para se falar de funcionalidades psíquicas, vividos ou de consciência intencional. Muitos críticos, entre alguns deles citados no artigo, como Lévinas e Michel Henry, enfatizam que Husserl abre estas questões, mas não dá um tratamento adequado para elas. É o caso em que Henry destaca a hylé como componente necessário para a subjetividade absoluta aberto por Husserl, mas ao mesmo tempo abandonado por ele.

A ocorrência dessa interpretação se deve ao fato de que Husserl deixou esses pressupostos em aberto, direcionando-se cada vez mais para as funcionalidades das noeses e para aquilo que é mais próprio do sujeito. Ademais, na concepção do fenomenólogo, todos esses pressupostos para aparecerem precisam, em algum momento, estarem em correlação com a consciência. Sem a explicitação intencional não há como saber destes pressupostos, e sem esses pressupostos não há aparecer propriamente dito. Portanto, é necessário considerar os pressupostos como eles se dão em si mesmos, e de que modo eles se entrelaçam na consciência. Como na questão do outro, por exemplo, é necessário partir não de uma intencionalidade que dê sentido e compreenda o outro, mas do próprio momento em que o outro entra na percepção, que se evidencia no organismo estranho algo que não se pode reduzir ou objetivar. Assim 
como o si mesmo não se faz objetivo, outrem da mesma forma se dá como estranho, afeta e coloca em questionamentoa funcionalidade e atividade de uma subjetividade, em que somente é possível conviver e associar-se reciprocamente.

\section{REFERÊNCIAS}

ALVES, Pedro M. S. Percepção e passividade. In: KORELC, Martina; SANTORO, Thiago Suman (org). Husserl: questões metafísicas. Goiana: Gráfica UFG, 2019, p. 1747.

BICEAGA, Victor. The Concept of Passivity in Husserl's Phenomenology. Contributions to Phenomenology 60. Dordrecht: Springer, 2010.

DEPRAZ, Natalie. Compreender Husserl. Tradução de Fábio dos Santos. Petrópolis: Vozes, 2007.

FABRI, Marcelo. Fenomenologia e Cultura: Husserl, Lévinas e a motivação ética do pensar. Porto Alegre: EDIPUCRS, 2007.

FERRER, Urbano; SÁNCHEZ-MIGALLÓN, Sergio. La ética de Edmund Husserl. Sevilla: Themata-Plaza y Valdés, 2011.

GOOSKENS, Geert. Towards a Responsive Subject: Husserl on Affection. In: Tymieniecka AT. (eds). Transcendentalism Overturned. Analecta Husserliana (The Yearbook of Phenomenological Research), vol 108. Dordrecht: Springer, 2011, p. 182-193.

HENRY, Michel. Fenomenología material. Traducción de Javier Teira y Roberto Ranz. Madrid: Encuentro, 2009.

. Fenomenologia não-intencional: tarefa para uma fenomenologia futura.

Tradutor José Rosa. Lusofia, $2006 . \quad$ Disponível em: <http://www.lusosofia.net/textos/michel_henry_fenomenologia_nao_intencional.pdf $>$. Acesso em: 28 jun. 2020.

HUSSERL, Edmund. Conferências em Paris. Tradução de António Fidalgo e Artur Morão. Lisboa: Edições 70, 1992.

Ideas relativas a una fenomenologia pura y una filosofia fenomenológica: livro segundo, investigación fenomenológica sobre la constituição. Traducción de Antônio Ziron. $2^{\mathrm{a}}$ ed. México: UNAM, Instituto de Investigaciones Filosóficas, 2005.

. Ideias para uma fenomenologia pura e para uma filosofia fenomenológica: introdução geral à fenomenologia pura. Tradução de Márcio Suzuki. 6 ed. São Paulo: Ideias e Letras, 2006.

Investigações Lógicas: investigações para a fenomenologia e a teoria do conhecimento. Tradução de Pedro M. S. Alves, Carlos A. Morujão. Rio de Janeiro: Forense, 2015. 
Investigações Lógicas: sexta investigação (elementos de uma elucidação fenomenológica do conhecimento). Seleção e tradução de Zeljko Loparic e Andréa Maria Altino de Campos Loparic. São Paulo: Abril Cultural, 1975.

. Meditações Cartesianas: introdução à fenomenologia. Tradução Frank de Oliveira. São Paulo: Madras, 2001.

LÉVINAS, Emmanuel. La teoria fenomenológica de la intuición. Traducción Tania Checchi. Salamanca: Ediciones Sígueme, 2004.

KOLREC, Martina. Teleologia e vontade segundo Husserl. Educação e Filosofia. v. 27, n. 53. Uberlândia, p. 343-382, jan./jun. 2013.

RICOEUR, Paul. Na escola da fenomenologia. Tradução de Ephraim Ferreira Alves. Petrópolis: Vozes, 2009.

SALANSKIS, Jean-Michel. Husserl. Tradução Carlos Alberto Ribeiro Moura. São Paulo: Estação Liberdade, 2006.

Recebido em: 07/07/2020

Aceito para publicação em: 26/09/2020 